\title{
Suture tape reinforcement of hamstring tendon graft reduces postoperative knee laxity after primary $A C L$ reconstruction
}

\author{
Christoffer von Essen ${ }^{1,2^{*}} \mathbb{0}$, Vasileios Sarakatsianos ${ }^{1,2}$, Riccardo Cristiani ${ }^{1,2}$ and Anders Stålman ${ }^{1,2}$
}

\begin{abstract}
Purpose: To evaluate and compare subjective and objective knee outcomes following hamstring tendon (HT) and quadriceps tendon (QT) anterior cruciate ligament reconstruction (ACLR) with or without suture tape (ST) reinforcement. It was hypothesized that the addition of an intra-articular synthetic augmentation with a ST would reduce postoperative knee laxity and graft ruptures after ACLR.
\end{abstract}

Methods: A 1:1 matched-cohort comparison of patients who underwent HT and QT autograft ACLR with or without ST reinforcement was performed. Patients with ST reinforcement were consecutively assigned to the study groups until a number of 20 in each group was achieved. Medical records were reviewed for demographic characteristics and additional injuries. Laxity measurements with KT-1000, strength measurements and physical examination findings were collected both preoperatively and at 6 months and patient reported outcome (PRO) scores were collected both preoperatively and at 12 months, and comparison was made HT vs HT + ST and QT vs QT + ST. Reoperations and reruptures were recorded during the 24-month follow-up period.

Results: Overall, 80 patients who underwent ACLR were included. Patients with HT + ST had significant less laxity postoperatively compared to HT at 6 months, 1.9 vs $0.8 \mathrm{~mm}, p<0.05$. No differences were found between the QT and QT + ST group. At 6 weeks patients treated with ST, both QT and HT, had a significant deficit in flexion compared to those without ST. However, this resolved at 6 months. There were no significant differences between HT + ST vs HT, or QT + ST vs QT, regarding postoperative PROs or strength measurements. Furthermore, the incidence of subsequent surgery and graft rupture was not significantly different between the groups.

Conclusion: ACLR with $H T+S T$ reduces laxity at 6 months compared to ACLR without ST, a difference not seen when ACLR was performed using QT with or without ST. No other differences were seen between the two techniques comparing subjective and objective findings.

Level of evidence: Level III.

Keywords: $A C L, A C L$ reconstruction, suture tape reinforcement

\footnotetext{
*Correspondence: Christoffer.vonessen@gmail.com

${ }^{2}$ Capio Artro Clinic, FIFA Medical Centre of Excellence, Sophiahemmet

Hospital, Valhallavägen 91, 11486 Stockholm, Sweden

Full list of author information is available at the end of the article
}

\section{Introduction}

Anterior cruciate ligament (ACL) reconstruction (ACLR) is a common orthopedic procedure, aiming at reducing knee instability. Although ACLR techniques have developed over the years and are today performed with an anteromedial femoral drilling technique, allowing a more anatomical positioning of the graft, the risk for subsequent surgery is still high [1,2]. An ACL graft 
tear is detrimental to patient outcomes following ACLR. Systematic reviews indicate that one can expect a failure rate between 3.5 and $7 \%$ of autografts, increasing up to $10-28 \%$ in a high-risk population [3-6]. The rates of ACL revision surgery have been reported at $2-3 \%$ within the first two to three years and an overall revision rate of approximately $4 \%$ is reported in the Swedish Knee Ligament Registry (SKLR). Furthermore, it is evident that the outcome after revision ACLR is inferior to that of a primary ACLR [7-11].

In Sweden, a hamstring graft (HT) is utilized in more than $85 \%$ of ACLRs, but quadriceps graft (QT) is gaining popularity [12]. Proponents of HT have reported minor donor-site morbidity, good tissue strength and easy access $[13,14]$, but with HT there is a high variability in the diameter of the graft received and a smaller diameter has been associated with a higher risk of graft failure $[15,16]$. HTs are also associated with an increased risk of increased knee laxity after primary ACLR $[17,18]$. The QT has shown to be a good alternative, with comparable outcomes and failure rates as well as the possibility to customize graft diameter [13, 19-21].

Graft augmentation was first introduced in the 80 s to increase tensile strength of the graft, but outcome data showed high failure rate and complications [22, 23]. However, more recently reinforcement with suture tape (ST) has been described to improve clinical outcomes and is thought to support the graft after ACLR [24, 25]. ST reinforcement has been used in various ligament repairs and reconstructions [26-29]. The ST is composed of an ultrahigh-molecular-weight polyethylene/polyester tape that is collagen coated to increase tissue integration and proposed advantages include protection of the graft during the proliferation, maturation, and ligamentization phases of healing [24, 25].

Only a few studies have compared HT ACLR with or without ST reinforcement and none using QT [30, 31].

The optimal surgical methods, graft choice and rehabilitation for ACLR have not yet been established. Rehabilitation must be fine-tuned in order to limit strain on the graft during graft incorporation and maturation. Although ACLR allows return to sports for the majority of patients [32], there is a risk of suffering a new injury or developing persistent laxity [33]. As such there remains potential for improvements in the treatment of these patients.

The purpose of this study was to compare subjective and objective outcomes for patients undergoing ACLR with either a HT or QT graft, with or without complementary ST. It was hypothesized that the addition of an intra-articular synthetic augmentation of the graft with a ST would reduce the risk of residual laxity and graft rupture after ACLR.

\section{Material and method}

Ethical approval for this study was obtained from the regional ethics committee, Karolinska Institutet 2017-401/31.

Patients presenting with an isolated ACL deficiency at the orthopedic outpatient clinic were assessed and received standardized written and oral information about the trial. Informed consent was obtained from each patient prior to participation to the study. Inclusion criteria were: Physical examination and magnetic resonance imaging (MRI) showing ACL injury, age between 18 and 40 years, active participation in pivoting sports and an ambition to return to the same sport. Exclusion criteria were: (1) previous ACL injuries to the ipsi- or contralateral knee, (2) multi-ligament injuries.

After patient and surgeon agreed on ACLR and graft choice, the patients were consecutively assigned to the study groups until a number of 20 patients with HT graft and ST and 20 patients with QT and ST were achieved.

The patients were then matched in a 1:1 ratio to a control group (age $+/-2$ years, gender) consisting of patients who underwent surgery at the clinic during the same time frame and with the same surgical technique, apart from the ST reinforcement, Fig. 1.

\section{Surgical technique}

Patients included in the study underwent anatomical single-bundle ACLR with autologous HT graft or midportion, full-thickness, all-soft tissue QT graft, with or without the addition of an independent ST (fiber tape $2.0 \mathrm{~mm}$, AR-7237, Arthrex, Naples, FL). Surgery was performed by one of two experienced knee surgeons.

The HT graft was harvested through a short, anteromedial oblique incision, a semitendinosus autograft was used in all cases and all grafts were between 8 and $10 \mathrm{~mm}$ in diameter as a quadruple.

The QT was harvested at full depth from a position slightly lateral to the central part of the patella. A graft with one-centimeter width was harvested with a length of seven centimeters and cut with a quad tendon graft cutting guide and quad tendon stripper/cutter (Arthrex Inc., Naples, FL) without the use of a bone-plug.

The graft ends were prepared using a SpeedWhip ripstop technique with No. 2 FiberLoop with a FiberTag (FiberLoop ${ }^{\circledR}$ with FiberTag ${ }^{\text {TM }}$ Suture, Arthrex, Inc., Naples, FL). Graft diameter was $10 \mathrm{~mm}$.

Suspensory fixation was used on both sides, a TightRope ${ }^{\circledR}$ RT (Arthrex, Inc., Naples, FL) was used on the femoral side, and a TightRope ${ }^{\circledR}$ ABS (Arthrex, Inc., Naples, FL) with a 14- or 20-mm button on the tibial side.

For the ST-reinforced grafts, the reinforcement was done after graft preparation with a FiberTape ${ }^{\circledR}$ (fiber tape 2,0 mm, AR-7237, Arthrex, Naples, FL) intended 


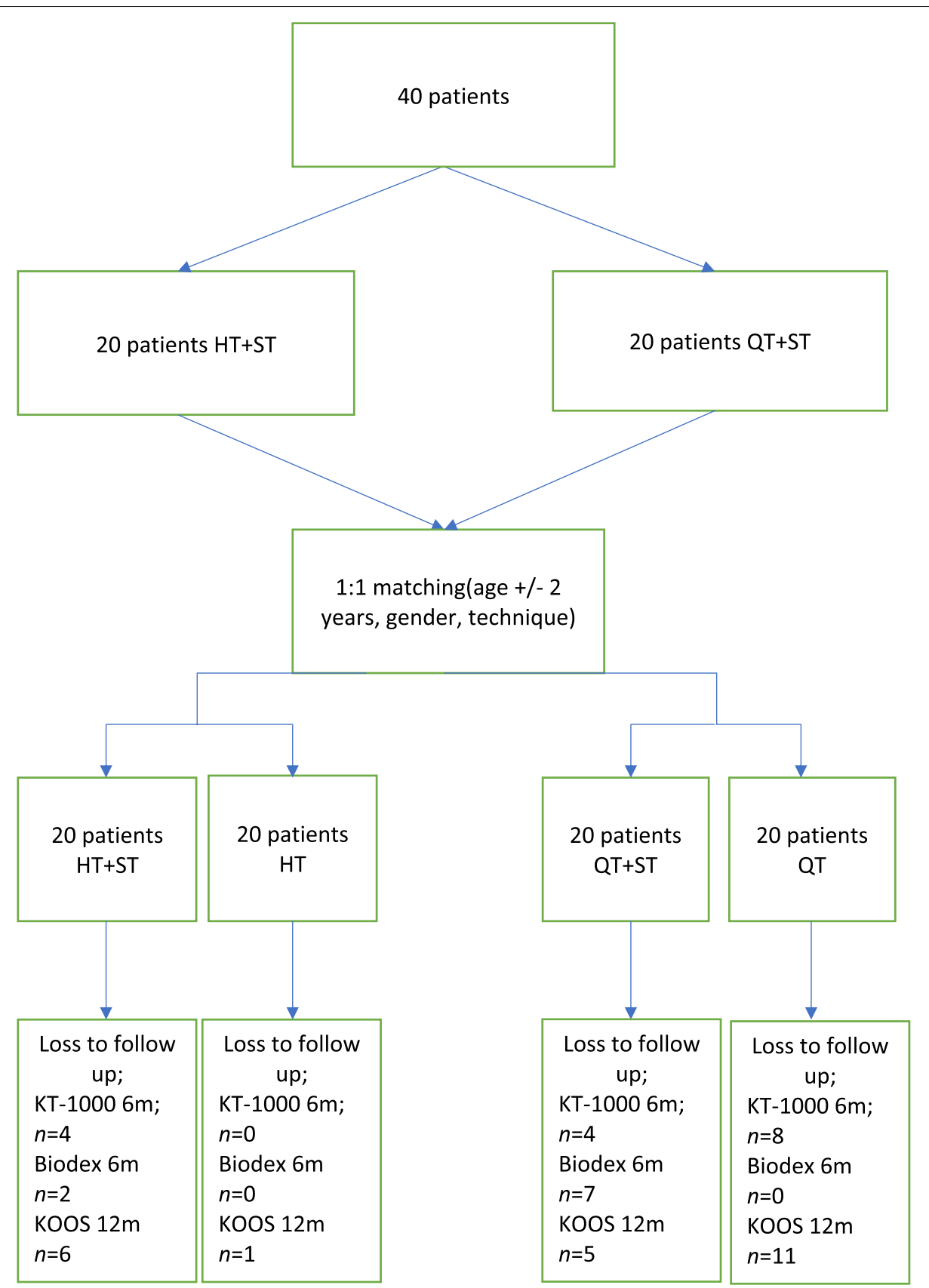

Fig. 1 Flow chart. KOOS, Knee injury and Osteoarthritis Outcome Score; HT, hamstring tendon; ST, suture tape; QT,quadriceps tendon

to be an internalbrace ${ }^{\mathrm{TM}}$ (Arthrex, Inc., Naples, FL). The FiberTape $^{\circledR}$ was passed through the proximal TightRope plate, Figs. 2, 3 and 4. The procedure was then similarly repeated at the distal end of the graft, with the exception that here a TightRope ABS button (Arthrex, Inc., Naples, FL) was used. The graft was placed in a graft tube (Arthrex Inc., Naples, FL) facilitating graft compression and shaping.
The femoral tunnel was drilled through the anteromedial portal in maximum knee flexion and was placed in the center of the native ACL footprint. For tibial tunnel placement, the ACL stump and the anterior horn of the lateral meniscus were used as landmarks.

The graft was first positioned in the femoral socket by tightening the Tightrope RT. A Tightrope ABS button was mounted on the ABS sling on the anterior tibia and 


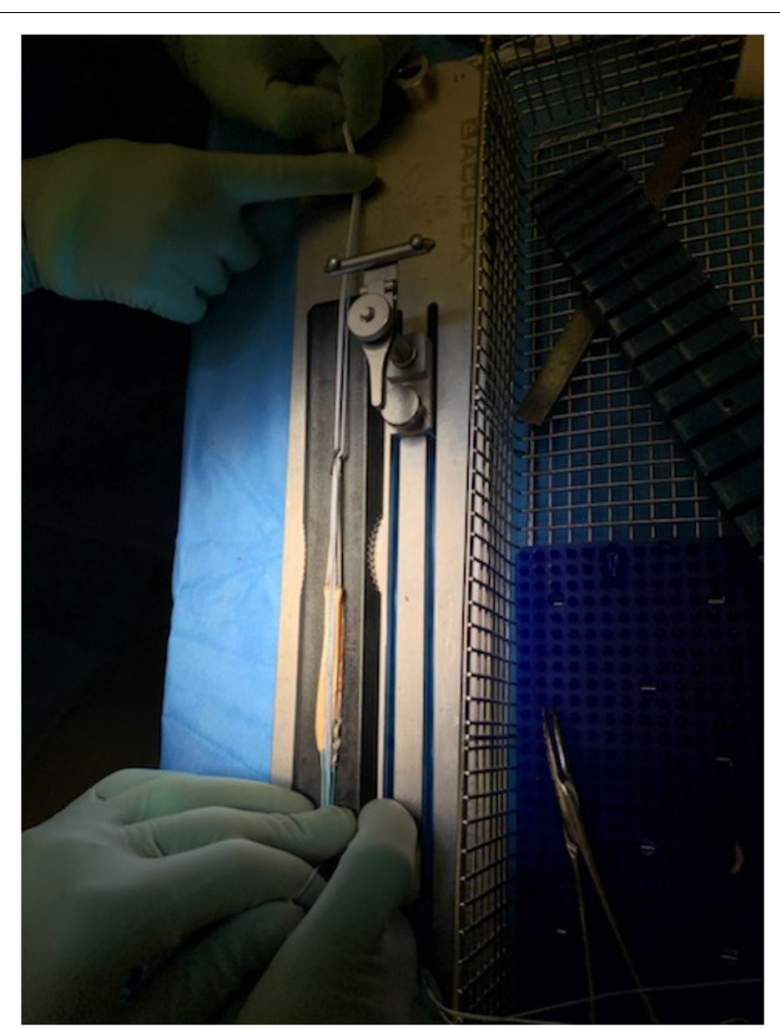

Fig. 2 Illustration of the reinforcement technique with FiberTape leading to a combined load distribution with the independent fixed FiberTape as a protective "safety belt" the FiberTape was also passed through the button. The graft was fixed over the ABS button in 30 degrees flexion and the FiberTape - InternalBrace - sutures were tied over the tightrope button in full extension. Primary tension of the graft combined with a fibertape supposedly allows for creating a protective safety belt for soft tissues grafts [24]. Tension was done according to the surgeons preference and isometry of the construct. When tensioned in full extension, the movement will not be affected $[34,35]$.

\section{Rehabilitation}

The rehabilitation was standardized according to the clinic's routine. Full weight bearing and full range of motion were allowed immediately postoperatively. Quadriceps strengthening was restricted to closed kinetic chain exercises during the first three months and thereafter rehabilitation was progressed with introduction of sport-specific exercises in order to enable return to the desired activity after 9 months and Biodex ${ }^{\circledR}$ testing showed $90 \%$ strength. If the menisci were in need of suturing, a brace was used with a fixed ROM $0-30^{\circ}$ for 2 weeks, $0-60^{\circ}$ for 2 weeks and $0-90^{\circ}$ for another 2 weeks, full weight-bearing was

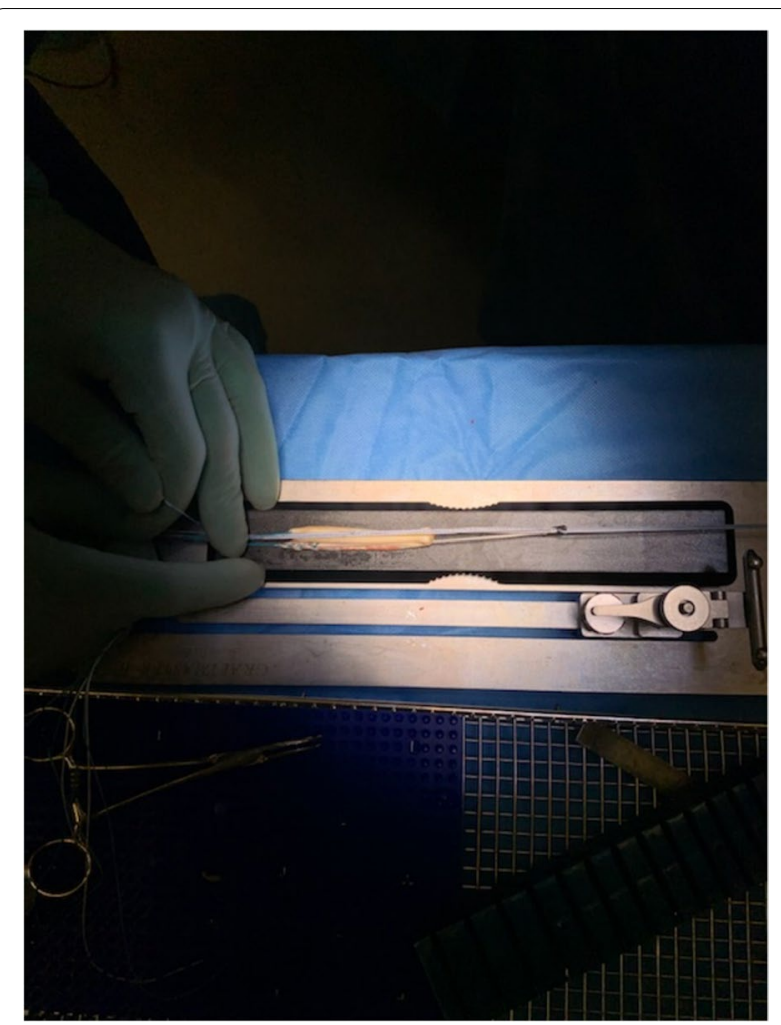

Fig. 3 Illustration of the reinforcement technique with FiberTape leading to a combined load distribution with the independent fixed FiberTape as a protective "safety belt"

permitted with the support of crutches during the first three weeks. Otherwise the same rehabilitation protocol was used.

\section{Patient evaluation}

Demographics were obtained at baseline and included age, gender, injured side, time from injury to surgery and concomitant injuries.

The Knee injury and Osteoarthritis Outcome Score (KOOS) [36], was obtained preoperatively and at 12 months postoperatively. Preoperative physical examination included: measurement of range of motion (ROM), Lachmann test, anterior drawer test and pivot shift test. Grading of the ROM, Lachmann, anterior drawer test and pivot shift test was done in accordance to the International Knee Documentation Committee (IKDC) knee examination form [37].

The KT-1000 arthrometer (MEDmetric, Corp., San Diego, CA, USA), was used to evaluate anterior knee laxity preoperatively and 6 months postoperatively. A standard $30 \mathrm{lbs}$. force, corresponding to a 134-N anterior tibial load, at $20^{\circ}$ of knee flexion, was applied. At least 3 measurements of each knee were made, and the median 


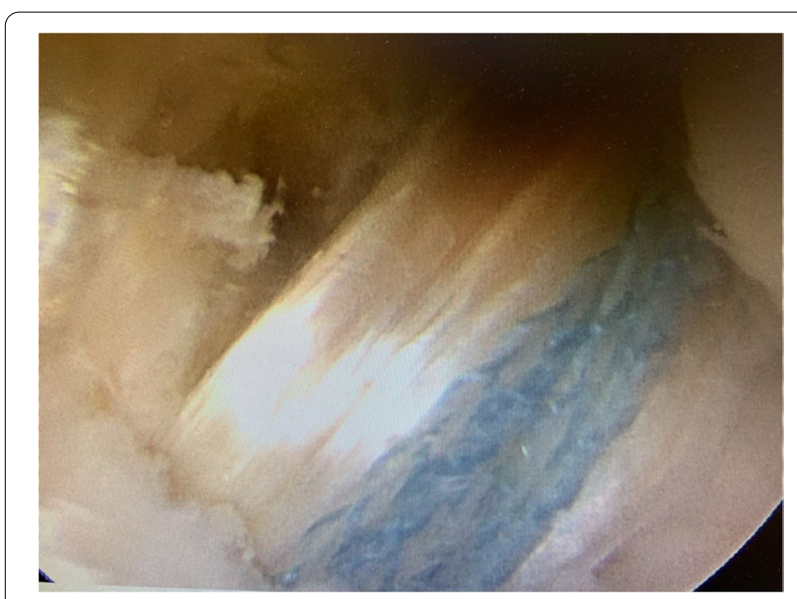

Fig. 4 Illustration of the reinforcement technique with FiberTape leading to a combined load distribution with the independent fixed FiberTape as a protective "safety belt"

value was registered. Postoperative difference in displacement (side-to-side (STS) difference) values were stratified according to the IKDC knee examination form in three groups: $\leq 2,3-5$, and $>5 \mathrm{~mm}$ [37]. "Surgical failure" was defined as an STS difference greater than $5 \mathrm{~mm}$ (IKDC grade $\mathrm{C}$ and $\mathrm{D}$ ).

Follow-up examinations at the clinic with visits to the surgeon and physiotherapist were performed at 6 weeks and 6 months postoperatively. At the follow up visits, patients underwent a full physical examination and at 6 months isokinetic strength was also measured with Biodex system 3 (Biodex Medical Systems, Shirley, New York, USA) [38].

Additionally, ACL graft failures, contralateral ACL ruptures and meniscal repair failures with necessity of revision meniscus surgery were recorded during the 24-month study period.

\section{Statistical analysis}

For statistical analysis, SPSS ${ }^{\circledR} 25.0$ (IBM SPSS Statistics, New York, USA) for Mac was used. Comparisons were made in pairs, HT vs. HT + ST and QT vs. QT + ST. To compare parametic and nonparametic variables between the groups the independent $\mathrm{t}$-test and Mann-Whitney $\mathrm{U}$ test were used. Nominal variables were tested by the Pearson Chi-squared test. Paired-sampled $t$ test was used for Longitudinal statistics for normally distributed scale variables. The significance level was set at $p<0.05$.

To determine the effect size and the power of the study, a post hoc power analysis using G*Power 3.1.9.2 (Franz Paul, Kiel, Germany) was used. Based on laxity with KT1000 at 6 weeks follow-up, the analysis revealed that for HT, a sample size of 20 patients in each group would yield a power of $61 \%$ to detect a $5 \%$ significance level in laxity and an effect size of 0.73 was obtained. The total sample size needed for a power $80 \%$ would be 62 patients, 31 in each group. For QT, a sample size of 20 patients in each group would yield a power of $5 \%$ to detect a $5 \%$ significance level in laxity and an effect size of 0.06 was obtained. The total sample size needed for a power $80 \%$ with QT would be 8140 patients, 4070 in each group.

\section{Results}

Demographic data of the study groups are displayed in Table 1. No significant differences were present among the groups.

\section{Laxity}

The mean preoperative and postoperative anterior STS difference showed that the HT with ST had significantly less laxity postoperatively compared with HT alone, no difference was found between the QT with or without ST, Fig. 5a-b. No group had an STS difference greater than $5 \mathrm{~mm}$ (surgical failure). Almost $70 \%$ of the patients had less than $2 \mathrm{~mm}$ STS difference in the HT + ST group, Table 2.

Table 1 Patient characteristics

\begin{tabular}{|c|c|c|c|c|c|c|}
\hline & $\mathrm{HT}+\mathrm{ST} n=20$ & HT Control $n=20$ & $p$-value & $\mathrm{QT}+\mathrm{ST} n=20$ & QT Control $n=20$ & $p$-value \\
\hline Age, mean (range) & $28.7(17-42)$ & $29.1(17-44)$ & n.s. & $29.6(18-48)$ & $29.2(18-48)$ & n.s. \\
\hline \multicolumn{7}{|l|}{ Sex } \\
\hline Male & $11(55)$ & $11(55)$ & & $12(60)$ & $12(60)$ & \\
\hline Female & $9(45)$ & $9(45)$ & & $8(40)$ & $8(40)$ & \\
\hline Medial meniscus resection & $2(10)$ & $2(10)$ & n.s & $2(10)$ & $2(10)$ & n.s \\
\hline Medial meniscus repair & $7(35)$ & $4(20)$ & n.s & $3(15)$ & $2(10)$ & n.s \\
\hline Lateral meniscus resection & $6(30)$ & $4(20)$ & n.s & $1(5)$ & $3(15)$ & n.s \\
\hline Lateral meniscus repair & $1(5)$ & $2(10)$ & n.s & $1(5)$ & $1(5)$ & n.s \\
\hline Cartilage injury & $1(5)$ & $2(10)$ & n.s & $3 / 20$ & $4(20)$ & n.s \\
\hline
\end{tabular}

Data are reported as $\mathrm{n}(\%)$, unless otherwise indicated

HT Hamstring tendon, ST Suture tape, QT quadriceps tendon 


\section{Objective results}

At 6 weeks patients treated with both QT $+\mathrm{ST}$ and $\mathrm{HT}+\mathrm{ST}$ had a significant deficit in flexion. This difference resolved at 6 months, Table 3.

No differences were found in hydrops, clinical laxity or in strength measurements between the groups, Table 3.

\section{Patient reported outcomes}

Figure 6 shows KOOS scores preoperatively and at 12 months postoperatively. There were no significant differences between the groups. Scores significantly increased from preoperatively to 12 months.

\section{Graft rupture and subsequent surgery}

All patients with graft rupture reported a new trauma. The incidence of subsequent surgery and graft rupture did not differ significantly between the groups, Table 4 . In the $\mathrm{HT}+\mathrm{ST}$ group, 2 patients underwent synovectomy due to pain and flexion deficit. In the QT control group 1 patient had a graft rupture after a new trauma 18 months after the index surgery, however, no further surgery was performed.
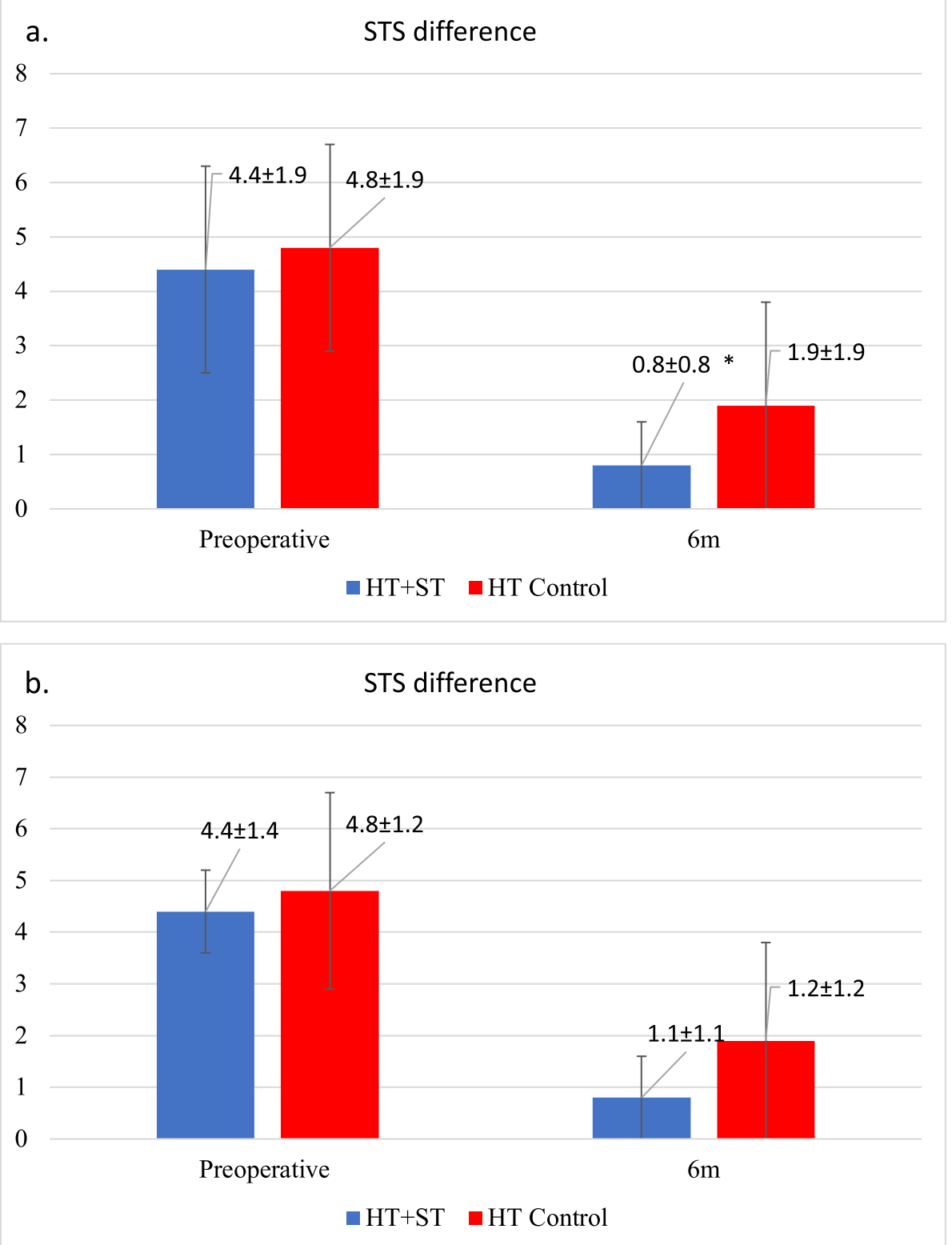

Fig. 5 a-b Mean anterior \pm SD STS difference, Values are displayed in mm. HT, hamstring tendon; ST, suture tape; QT, quadriceps tendon. * Statistically significant 
Table 2 Stratified KT-1000 values according to IKDC at $6 \mathrm{~m}$

\begin{tabular}{lllllll}
\hline & HT ST $\boldsymbol{n}=\mathbf{1 6}$ & HT Control $\boldsymbol{n}=\mathbf{2 0}$ & $\boldsymbol{p}$-value & QT ST $\boldsymbol{n = 1 6}$ & QT Control $\boldsymbol{n}=\mathbf{1 2}$ & $\boldsymbol{p}$-value \\
\hline$<2 \mathrm{~mm}$ & $11(69)$ & $8(40)$ & n.s. & $9(56)$ & $6(50)$ & n.s. \\
$2-5 \mathrm{~mm}$ & $5(31)$ & $12(60)$ & n.s. & $7(44)$ & $0(50)$ & n.s. \\
$>5 \mathrm{~mm}$ & 0 & 0 & & 0 & 0 &
\end{tabular}

Data are reported as $\mathrm{n}(\%)$, unless otherwise indicated

IKDC The International Knee Documentation, HT Hamstring tendon, ST Suture tape, QT quadriceps tendon

In the QT + ST group, 2 patients experienced discomfort and one had a slight flexion deficit, -10 degrees, diagnostic arthroscopies were performed in both cases without any findings. After surgeries, the discomfort subsided. One patient suffered a new trauma during snowboarding. There was a small new cartilage injury on the lateral femoral condyle, and the patient underwent microfracture surgery. The graft was intact, but the ST was torn.

\section{Discussion}

The principal finding in this matched-cohort comparison pilot study was that the use of an HT graft with ST reinforcement significantly reduced laxity with KT-1000 at
6 months compared with HT alone. However, at 6 months no differences in laxity were seen with the QT + ST compared to QT. Further, this study did not identify significant differences in re-rupture and reoperation rates, objective measurements and PROs between the groups.

The results of this study showed neither a higher complication rate nor hydrops in the cohort with ST compared to the control cohort. This is in contrast with the results reported in the 1980s, when the use of augmentation led to high rates of failure and noninfectious knee synovitis/effusion [22]. However, more recent studies have shown similar results regarding synovitis [30, 31]. The re-rupture rates were also low after 2 years.

Table 3 Patient objective outcome and muscle strength

\begin{tabular}{|c|c|c|c|c|c|c|}
\hline & $\mathrm{HT}+\mathrm{ST} n=20$ & HT control $n=20$ & $p$-value & $\mathrm{QT}+\mathrm{ST} n=20$ & QT control $n=20$ & $p$-value \\
\hline \multicolumn{7}{|l|}{$\mathrm{ROM}^{\mathrm{a}}$} \\
\hline \multicolumn{7}{|l|}{ Loss of extension } \\
\hline Preop & 0 & 0 & n.s. & 0 & 0 & n.s. \\
\hline $6 w$ & $6(30)$ & $4(20)$ & n.s. & $4(20)$ & $2(10)$ & n.s. \\
\hline $6 \mathrm{~m}$ & 0 & 0 & n.s. & 0 & 0 & n.s. \\
\hline \multicolumn{7}{|l|}{ Loss of flexion } \\
\hline Preop & 0 & 0 & n.s. & 0 & 0 & n.s. \\
\hline $6 w$ & $11(55)$ & $4(20)$ & 0.029 & $10(50)$ & $4(20)$ & 0.046 \\
\hline $6 \mathrm{~m}$ & $1(5)$ & $2(10)$ & n.s. & $1(5)$ & $1(5)$ & n.s. \\
\hline \multicolumn{7}{|l|}{ Hydrops $^{b}$} \\
\hline Preop & 0 & 0 & n.s. & 0 & 0 & n.s. \\
\hline $6 w$ & $12(60)$ & $9(45)$ & n.s. & $12(60)$ & $8(40)$ & n.s. \\
\hline $6 \mathrm{~m}$ & $2(10)$ & $1(5)$ & n.s. & $1(5)$ & $1(5)$ & n.s. \\
\hline \multicolumn{7}{|l|}{ Clinical laxity ${ }^{c}$ at $6 \mathrm{~m}$} \\
\hline Lachman & $4(20)$ & $3(15)$ & n.s. & $3(15)$ & $3(15)$ & n.s. \\
\hline Pivot Shift & 0 & 0 & n.s. & 0 & 0 & n.s. \\
\hline \multicolumn{7}{|l|}{ Biodex $6 \mathrm{~m} \mathrm{LSI} \geq 90 \%^{\mathrm{d}}$} \\
\hline Quadriceps strength & $5(28)$ & $5(25)$ & n.s. & $1(8)$ & $1(5)$ & n.s. \\
\hline Hamstring strength & $4(22)$ & $6(30)$ & n.s. & $10(77)$ & $12(60)$ & n.s. \\
\hline
\end{tabular}

Values are displayed as number and (\%) percentage

$H T$ Hamstring tendon, ST Suture tape, QT Quadriceps tendon

${ }^{\text {a }}$ ROM at 6 weeks and 6 months is compared to pre-op values in the operated knee

${ }^{\mathrm{b}}$ Hydrops according to IKDC

c Assesses stability of knee at rest result range from 0 (normal stability) to 1 (increased instability)

d The limb symmetry indexes (LSIs) of the peak quadriceps and hamstring torque were calculated as [involved limb/uninvolved limb $\times 100$ ] for each test. The achievement of a symmetrical isokinetic muscle strength was defined as performing at least $90 \%$ of the contralateral leg (LSI $\geq 90 \%)$ 


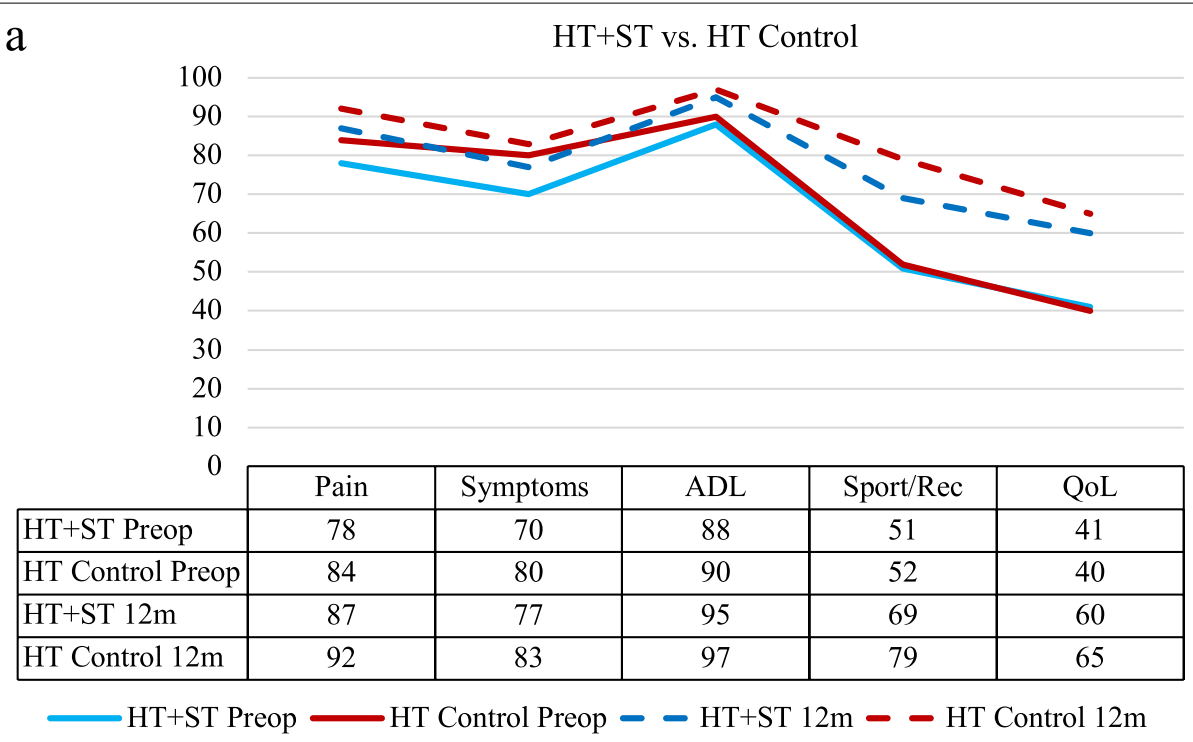

b

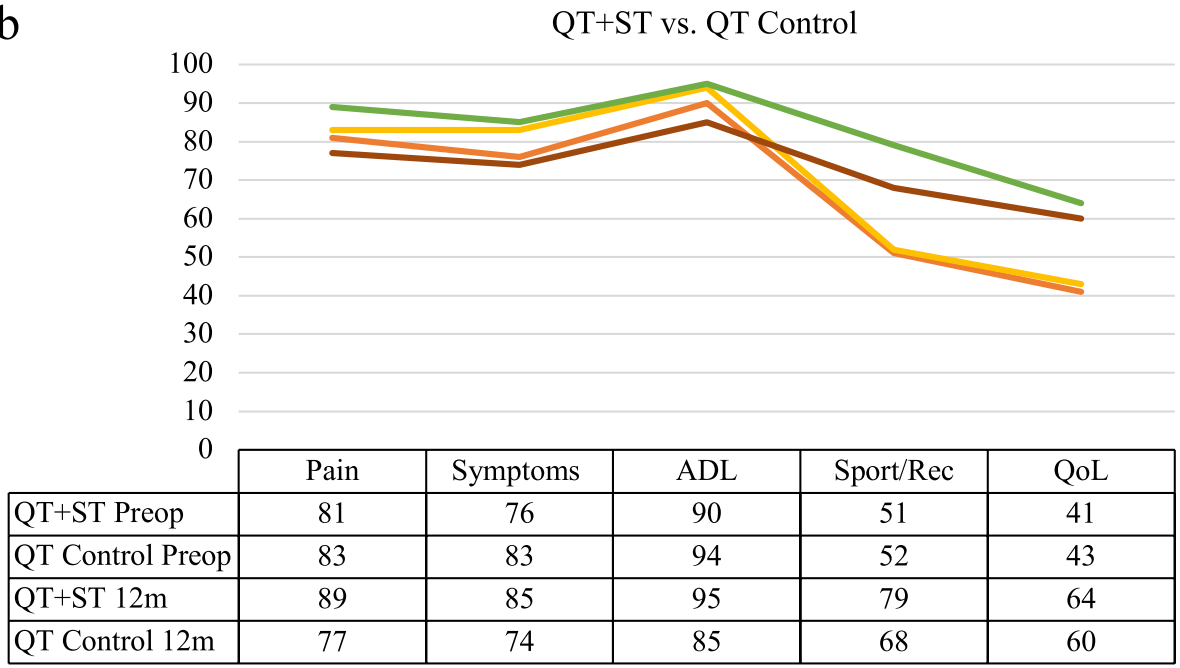

QT+ST Preop - QT Control Preop - QT+ST 12m - QT Control 12m

Fig. 6 a-b, Mean KOOS score pre and postoperative at $12 \mathrm{~m}$ for the groups. KOOS, Knee injury and Osteoarthritis Outcome Score; HT, hamstring tendon; ST, suture tape; QT,quadriceps tendon

One of the primary goals of ST reinforcement in ACLR is protection of the graft, especially early in the healing process. The ST is supposed to act as a safety belt that supports the graft during the remodeling phase offering protection from high strains [39]. There is a high risk of subsequent injuries when returning to sport after ACLR $[40,41]$ suggesting that the reconstructed graft cannot tolerate the necessary forces. Graft ligamentization is a slow process and it is not exactly known how long it takes before the graft resembles the properties of the native ACL [42]. Biomechanical studies on ST reinforcement showed reduced elongation of the graft $(24,35)$, which can also be seen in this study as the HT + ST graft showed significant reduced laxity compared to the control group [24, 43]. The surgical technique of independent reinforcement with a ST to the graft is not technically demanding and can be done with minimal extra time during graft preparation. It does, however, have the potential to over constrain the knee, if the ST is tensioned too tightly. This could result in stiffness or loss of ROM and possibly also interfere with the incorporation of the graft. Applying the ST separately and having separate fixation allows the graft to function independantly within a normal ROM, thus avoiding overconstraint of 
Table 4 Re-operations and re-rupture. Two years follow-up

\begin{tabular}{|c|c|c|c|c|c|c|}
\hline & $\mathrm{HT}+\mathrm{ST} n=20$ & HT control $n=20$ & $p$-value & $\mathrm{QT}+\mathrm{ST} n=20$ & QT control $n=20$ & $p$-value \\
\hline Re-operation ${ }^{\mathrm{a}}$ & $5(25)$ & $4(20)$ & n.s. & $5(25)$ & $4(20)$ & n.s. \\
\hline Confirmed ACL re-rupture & $1(5)$ & 0 & n.s. & 0 & $2(10)$ & n.s. \\
\hline Synovectomy & $2(10)$ & 0 & & 0 & 0 & \\
\hline Revision ACLR & $1(5)$ & 0 & & 0 & $1(5)$ & \\
\hline Cyclops & $1(5)$ & $2(10)$ & & 0 & $1(5)$ & \\
\hline Meniscal procedure & $1(5)$ & $2(10)$ & & 0 & $2(10)$ & \\
\hline Notchplasty & 0 & 0 & & $1(5)$ & 0 & \\
\hline Cartilage procedure & 0 & 0 & & $2(10)$ & 0 & \\
\hline Diagnostic arthroscopy & 0 & 0 & & $2(10)$ & 0 & \\
\hline
\end{tabular}

Values are displayed as number and (\%) percentage

HT Hamstring tendon, ST Suture tape, QT Quadriceps tendon

a Number of patients, one patient can have more than one reoperation

the construct [34, 35]. This can be seen as a safety-belt that doesn't inhibit the graft healing process but helps in avoiding unintended excessive graft strain during rehabilitation or return to sport. In this study, both groups with ST had a significant loss of flexion at 6 weeks postoperatively compared to the control group. Possibly the graft with ST needed more time to adapt. It is possible that applying a ST can give a temporary over constraint of the knee. This loss of motion did, however, resolve at 6 months.

There were no differences in postoperative KOOS subscales scores at 1 year. However, there were significant improvements for all groups on all subscales from preoperative level.

The main strength of this study was that we could show that the technique is feasible without any" red flags" that previously have been described with other augmentation techniques [22].

Being a pilot study there are limitations. There was no randomization between the groups, neither were the patients nor surgeons blinded to the treatment and reported outcomes could have been subject to bias. There is a limitation that the KOOS values are only at oneyear follow up, even though KOOS results are shown to be equivalent between 1 and 2 years in register data [44]. Another limitation is that the graft tension was not standardized.

A post hoc analysis revealed a high effect size for the ACLR with HT graft and ST, but for the ACLR with QT graft and ST the effect size was very low. The results from the post hoc analysis revealed that the total sample size needed to detect a difference in laxity for the $\mathrm{HT}+\mathrm{ST}$ was 62 patients if desired power is set at $80 \%$.

The results from this pilot study are important and show that further studies are feasible, and that there are potential benefits regarding laxity, foremost with $\mathrm{HT}+\mathrm{ST}$.

\section{Conclusions}

Anterior cruciate ligament reconstruction with $\mathrm{HT}+\mathrm{ST}$ reduces laxity compared to ACLR without $\mathrm{ST}$, a difference not seen when ACLR was performed with QT + ST compared without ST. No other differences were seen between the two techniques comparing subjective and objective findings.

\section{Acknowledgements \\ Dr. McCallum for the help of editing and correcting the manuscript for English-language use.}

\section{Authors' contributions}

CvE., V.S., R.C. and A.S. contributed to the design and implementation of the research, to the analysis of the results and to the writing of the manuscript. All authors have read and agreed to the published version of the manuscript.

\section{Funding}

Open access funding provided by Karolinska Institute. Arthrex Inc. provided funding for this study.

Availability of data and materials

The data presented in this study are available on request from the corresponding author.

\section{Declarations}

Ethics approval and consent to participate

This study was approved from the Regional Ethics Committee, Karolinska Institutet, Diarie number: 2017-401/31.

\section{Consent for publication}

Informed consent was obtained by each patient.

\section{Competing interests}

Each author declares that no possible conflict of interest (financial or not financial) exist in connection with this study.

\section{Author details}

${ }^{1}$ Department of Molecular Medicine and Surgery, Stockholm Sports Trauma Research Center, Karolinska Institutet, Stockholm, Sweden. ${ }^{2}$ Capio Artro Clinic, 
FIFA Medical Centre of Excellence, Sophiahemmet Hospital, Valhallavägen 91 11486 Stockholm, Sweden.

Received: 7 September 2021 Accepted: 11 February 2022 Published online: 23 February 2022

\section{References}

1. Cristiani R, Mikkelsen C, Edman G, Forssblad M, Engström B, Stålman A (2020) Age, gender, quadriceps strength and hop test performance are the most important factors affecting the achievement of a patientacceptable symptom state after $\mathrm{ACL}$ reconstruction. Knee Surg Sports Traumatol Arthrosc 28:369-380

2. Lord L, Cristiani R, Edman G, Forssblad M, Stålman A (2020) One sixth of primary anterior cruciate ligament reconstructions may undergo reoperation due to complications or new injuries within 2 years. Knee Surg Sports Traumatol Arthrosc. https://doi.org/10.1007/s00167-020-06127-w

3. Gabler CM, Jacobs CA, Howard JS, Mattacola CG, Johnson DL (2016) Comparison of Graft Failure Rate Between Autografts Placed via an Anatomic Anterior Cruciate Ligament Reconstruction Technique: A Systematic Review, Meta-analysis, and Meta-regression. Am J Sports Med 44:1069-1079

4. Magnussen RA, Meschbach NT, Kaeding CC, Wright RW, Spindler KP (2015) ACL Graft and Contralateral ACL Tear Risk within Ten Years Following Reconstruction: A Systematic Review. JBJS Rev 3(1):e3

5. Rousseau R, Labruyere C, Kajetanek C, Deschamps O, Makridis KG, Djian P (2019) Complications After Anterior Cruciate Ligament Reconstruction and Their Relation to the Type of Graft: A Prospective Study of 958 Cases. Am J Sports Med 47:2543-2549

6. Samuelsen BT, Webster KE, Johnson NR, Hewett TE, Krych AJ (2017) Hamstring Autograft versus Patellar Tendon Autograft for ACL Reconstruction: Is There a Difference in Graft Failure Rate? A Meta-analysis of 47,613 Patients. Clin Orthop Relat Res 475:2459-2468

7. Cristiani R, Engström B, Edman G, Forssblad M, Stålman A (2019) Revision anterior cruciate ligament reconstruction restores knee laxity but shows inferior functional knee outcome compared with primary reconstruction. Knee Surg Sports Traumatol Arthrosc 27:137-145

8. Dunn WR, Lyman S, Lincoln AE, Amoroso PJ, Wickiewicz T, Marx RG (2004) The effect of anterior cruciate ligament reconstruction on the risk of knee reinjury. Am J Sports Med 32:1906-1914

9. Lind M, Menhert F, Pedersen AB (2009) The first results from the Danish $A C L$ reconstruction registry: epidemiologic and 2 year follow-up results from 5,818 knee ligament reconstructions. Knee Surg Sports Traumatol Arthrosc 17:117-124

10. Mohan R, Webster KE, Johnson NR, Stuart MJ, Hewett TE, Krych AJ (2018) Clinical Outcomes in Revision Anterior Cruciate Ligament Reconstruction: A Meta-analysis. Arthroscopy 34:289-300

11. Snaebjörnsson T, Hamrin Senorski E, Svantesson E, Westin O, Persson A, Karlsson J et al (2019) Graft Fixation and Timing of Surgery Are Predictors of Early Anterior Cruciate Ligament Revision: A Cohort Study from the Swedish and Norwegian Knee Ligament Registries Based on 18,425 Patients. JB JS Open Access 4:e0037

12. The Swedish Knee Ligament Registry. The Swedish knee ligament registry Annual report 2019. 2019

13. Mouarbes D, Menetrey J, Marot V, Courtot L, Berard E, Cavaignac E (2019) Anterior Cruciate Ligament Reconstruction: A Systematic Review and Meta-analysis of Outcomes for Quadriceps Tendon Autograft Versus Bone-Patellar Tendon-Bone and Hamstring-Tendon Autografts. Am J Sports Med. https://doi.org/10.1177/0363546518 825340363546518825340

14. Widner M, Dunleavy M, Lynch S (2019) Outcomes Following ACL Reconstruction Based on Graft Type: Are all Grafts Equivalent? Curr Rev Musculoskelet Med. https://doi.org/10.1007/s12178-019-09588-w

15. Snaebjornsson T, Hamrin Senorski E, Ayeni OR, Alentorn-Geli E, Krupic F, Norberg F et al (2017) Graft Diameter as a Predictor for Revision Anterior Cruciate Ligament Reconstruction and KOOS and EQ-5D Values: A Cohort Study From the Swedish National Knee Ligament Register Based on 2240 Patients. Am J Sports Med 45:2092-2097
16. Spragg L, Chen J, Mirzayan R, Love R, Maletis G (2016) The Effect of Autologous Hamstring Graft Diameter on the Likelihood for Revision of Anterior Cruciate Ligament Reconstruction. Am J Sports Med 44:1475-1481

17. Cristiani R, Forssblad M, Engström B, Edman G, Stålman A (2018) Risk Factors for Abnormal Anteroposterior Knee Laxity After Primary Anterior Cruciate Ligament Reconstruction. Arthroscopy 34:2478-2484

18. Cristiani R, Sarakatsianos V, Engström B, Samuelsson K, Forssblad M, Stålman A (2019) Increased knee laxity with hamstring tendon autograft compared to patellar tendon autograft: a cohort study of 5462 patients with primary anterior cruciate ligament reconstruction. Knee Surg Sports Traumatol Arthrosc 27:381-388

19. Belk JW, Kraeutler MJ, Marshall HA, Goodrich JA, McCarty EC (2018) Quadriceps Tendon Autograft for Primary Anterior Cruciate Ligament Reconstruction: A Systematic Review of Comparative Studies With Minimum 2-Year Follow-Up. Arthroscopy 34:1699-1707

20. Lind M, Nielsen TG, Soerensen OG, Mygind-Klavsen B, Faunø P (2020) Quadriceps tendon grafts does not cause patients to have inferior subjective outcome after anterior cruciate ligament $(A C L)$ reconstruction than do hamstring grafts: a 2-year prospective randomised controlled trial. Br J Sports Med 54:183-187

21. Nyland J, Collis P, Huffstutler A, Sachdeva S, Spears JR, Greene J et al (2020) Quadriceps tendon autograft ACL reconstruction has less pivot shift laxity and lower failure rates than hamstring tendon autografts. Knee Surg Sports Traumatol Arthrosc 28:509-518

22. Batty LM, Norsworthy CJ, Lash NJ, Wasiak J, Richmond AK, Feller JA (2015) Synthetic devices for reconstructive surgery of the cruciate ligaments: a systematic review. Arthroscopy 31:957-968

23. Kennedy JC, Roth JH, Mendenhall HV, Sanford JB (1980) Presidential address. Intraarticular replacement in the anterior cruciate ligamentdeficient knee. Am J Sports Med 8:1-8

24. Bachmaier S, Smith PA, Bley J, Wijdicks CA (2018) Independent Suture Tape Reinforcement of Small and Standard Diameter Grafts for Anterior Cruciate Ligament Reconstruction: A Biomechanical Full Construct Model. Arthroscopy 34:490-499

25. Soreide E, Denbeigh JM, Lewallen EA, Thaler $R, X u$ W, Berglund $L$ et al (2019) assessment of high-molecular-weight polyethylene core suture tape for intra-articular ligament reconstruction: an animal study. Bone Joint J 101-B:1238-1247

26. Black AK, Schlepp C, Zapf M, Reid JB (2018) Technique for Arthroscopically Assisted Superficial and Deep Medial Collateral Ligament-Meniscotibial Ligament Repair With Internal Brace Augmentation. Arthrosc Tech 7:e1215-e1219

27. Dabis J, Wilson A (2019) Repair and Augmentation with Internal Brace in the Multiligament Injured Knee. Clin Sports Med 38:275-283

28. Gilmer BB, Crall T, DeLong J, Kubo T, Mackay G, Jani SS (2016) Biomechanical Analysis of Internal Bracing for Treatment of Medial Knee Injuries. Orthopedics 39:e532-e537

29. Hopper GP, Heusdens CHW, Dossche L, Mackay GM (2018) Posterolateral Corner Repair With Suture Tape Augmentation. Arthrosc Tech 7:e1299-e1303

30. Bodendorfer BM, Michaelson EM, Shu HT, Apseloff NA, Spratt JD, Nolton EC et al (2019) Suture Augmented Versus Standard Anterior Cruciate Ligament Reconstruction: A Matched Comparative Analysis. Arthroscopy 35:2114-2122

31. Parkes CW, Leland DP, Levy BA, Stuart MJ, Camp CL, Saris DBF et al (2021) Hamstring Autograft Anterior Cruciate Ligament Reconstruction Using an All-Inside Technique With and Without Independent Suture Tape Reinforcement. Arthroscopy 37:609-616

32. Kay J, Memon M, Marx RG, Peterson D, Simunovic N, Ayeni OR (2018) Over $90 \%$ of children and adolescents return to sport after anterior cruciate ligament reconstruction: a systematic review and meta-analysis. Knee Surg Sports Traumatol Arthrosc 26:1019-1036

33. Nagelli CV, Hewett TE (2017) Should Return to Sport be Delayed Until 2 Years After Anterior Cruciate Ligament Reconstruction? Biological and Functional Considerations. Sports Med 47:221-232

34. Wang JH, Kato Y, Ingham SJ, Maeyama A, Linde-Rosen M, Smolinski P et al (2012) Measurement of the end-to-end distances between the femoral and tibial insertion sites of the anterior cruciate ligament during knee flexion and with rotational torque. Arthroscopy 28:1524-1532 
35. Yoo YS, Jeong WS, Shetty NS, Ingham SJ, Smolinski P, Fu F (2010) Changes in ACL length at different knee flexion angles: an in vivo biomechanical study. Knee Surg Sports Traumatol Arthrosc 18:292-297

36. Roos EM, Roos HP, Ekdahl C, Lohmander LS (1998) Knee injury and Osteoarthritis Outcome Score (KOOS)--validation of a Swedish version. Scand J Med Sci Sports 8:439-448

37. Hefti F, Müller W, Jakob RP, Stäubli HU (1993) Evaluation of knee ligament injuries with the IKDC form. Knee Surg Sports Traumatol Arthrosc 1:226-234

38. Taylor NA, Sanders RH, Howick El, Stanley SN (1991) Static and dynamic assessment of the Biodex dynamometer. Eur J Appl Physiol Occup Physiol 62:180-188

39. Smith PA, Bradley JP, Konicek J, Bley JA, Wijdicks CA (2020) Independent Suture Tape Internal Brace Reinforcement of Bone-Patellar Tendon-Bone Allografts: Biomechanical Assessment in a Full-ACL Reconstruction Laboratory Model. J Knee Surg 33:1047-1054

40. Grindem H, Engebretsen L, Axe M, Snyder-Mackler L, Risberg MA (2020) Activity and functional readiness, not age, are the critical factors for second anterior cruciate ligament injury - the Delaware-Oslo ACL cohort study. Br J Sports Med 54:1099-1102

41. Grindem H, Snyder-Mackler L, Moksnes H, Engebretsen L, Risberg MA (2016) Simple decision rules can reduce reinjury risk by $84 \%$ after $A C L$ reconstruction: the Delaware-Oslo ACL cohort study. Br J Sports Med 50:804-808

42. van Groningen $B$, van der Steen MC, Janssen DM, van Rhijn LW, van der Linden AN, Janssen RPA (2020) Assessment of Graft Maturity After Anterior Cruciate Ligament Reconstruction Using Autografts: A Systematic Review of Biopsy and Magnetic Resonance Imaging studies. Arthrosc Sports Med Rehabil 2:e377-e388

43. Noonan BC, Bachmaier S, Wijdicks CA, Bedi A (2020) Independent Suture Tape Reinforcement of Tripled Smaller-Diameter and Quadrupled Grafts for Anterior Cruciate Ligament Reconstruction With Tibial Screw Fixation: A Biomechanical Full Construct Model. Arthroscopy 36:481-489

44. Samuelsson K, Magnussen RA, Alentorn-Geli E, Krupic F, Spindler KP, Johansson C et al (2017) Equivalent Knee Injury and Osteoarthritis Outcome Scores 12 and 24 Months After Anterior Cruciate Ligament Reconstruction: Results From the Swedish National Knee Ligament Register. Am J Sports Med 45:2085-2091

\section{Publisher's Note}

Springer Nature remains neutral with regard to jurisdictional claims in published maps and institutional affiliations.

\section{Submit your manuscript to a SpringerOpen ${ }^{\circ}$ journal and benefit from:}

- Convenient online submission

- Rigorous peer review

- Open access: articles freely available online

- High visibility within the field

- Retaining the copyright to your article 